\title{
The effect of root architecture and root loss through trenching on the anchorage of tropical urban trees (Eugenia grandis Wight).
}

\begin{abstract}
Eugenia grandis (Wight) is grown in urban environments throughout Malaysia and root systems are often damaged through trenching for the laying down of roads and utilities. We investigated the effect of root cutting through trenching on the biomechanics of mature $\mathrm{E}$. grandis. The force necessary to winch trees $0.2 \mathrm{~m}$ from the vertical was measured. Trenches were then dug at different distances $(1.5,1.0$ and $0.5 \mathrm{~m})$ from the trunk on the tension side of groups of trees. Each tree was winched sideways again and the uprooting force recorded. No trenches were made in a control group of trees which were winched until failure occurred. Critical turning moment (TMcrit) and tree anchorage rotational stiffness (TARS) before and after trenching were calculated. Root systems were extracted for architectural analysis and relationships between architectural parameters and TMcrit and TARS were investigated. No differences were found between TMcrit and trenching distance. However, in control trees and trees with roots cut at $1.5 \mathrm{~m}$, significant relationships did exist between both TMcrit and TARS with stem dimensions, rooting depth and root plate size. TARS was significantly decreased when roots were cut at $0.5 \mathrm{~m}$ only. Surprisingly, no relationships existed between TMcrit and TARS with any root system parameter when trenching was carried out at 0.5 or $1.0 \mathrm{~m}$. Our study showed that in terms of TARS and TMcrit, mechanical stability was not greatly affected by trenching, probably because rooting depth close to the trunk was a major component of anchorage.
\end{abstract}

Keyword: Anchorage rotational stiffness; Critical turning moment; Mechanical stability; Acclimazation; root eccentricity. 